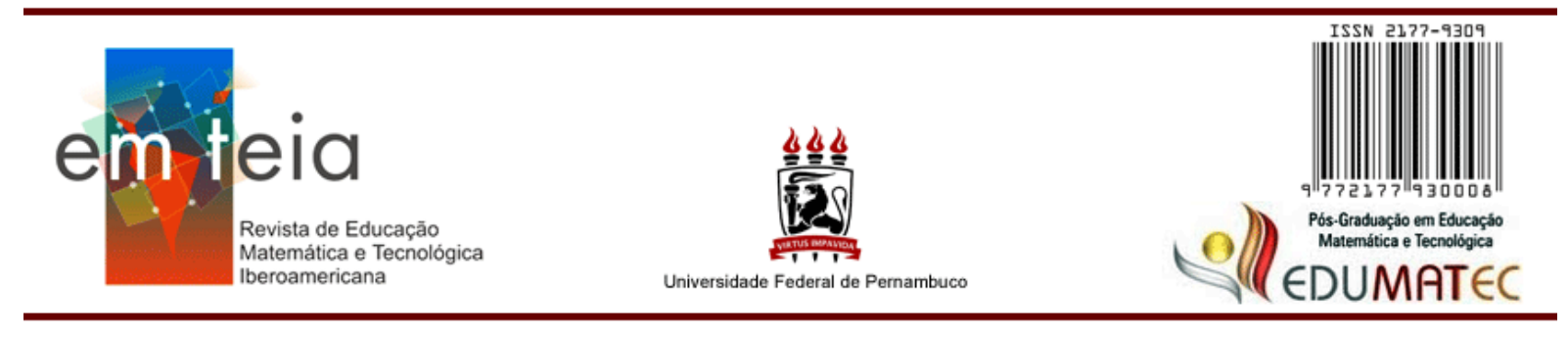

\title{
DOCÊNCIA ONLINE EM UM AMBIENTE VIRTUAL DE APRENDIZAGEM OU EM UM GRUPO DE UMA REDE SOCIAL? UMA DECISÃO POLÍTICA E TECNOLÓGICA
}

Teaching online in a virtual environment of learning or in a group of a social network? a political and technological decision

\author{
Marcelo Almeida Bairral \\ Professor - UFRRJ/PPGEduc \\ www.gepeticem.ufrrj.br \\ mbairral@ufrrj.br \\ Bruno Vieira Alves da Silva \\ Mestre em Educação - UFRRJ/PPGEduc \\ brunovieira009@hotmail.com
}

\section{Resumo}

Esse artigo é fruto de uma investigação (integrante de um projeto financiado pelo CNPq) que suscita reflexões sobre o uso de uma rede social como possível espaço de aprendizagem docente. Especificamente, ilustra particularidades entre um Ambiente Virtual de Aprendizagem (AVA) e um grupo fechado no Facebook. O grupo, intitulado Tecnologias e Inclusão Social, constituiu o coletivo de uma disciplina optativa de Mestrado em Educação do Programa de Pesquisa e Pós-Graduação em Educação, Contextos Contemporâneos e Demandas Populares (PPGEduc/UFRRJ), e foi composto por dez pós-graduandos com diferentes formações. A disciplina transcorreu em sua maior parte no Facebook e os participantes tiveram oportunidade de explorar as ferramentas disponibilizadas na rede e de refletir coletivamente a partir de propostas diversas de discussão oriundas das leituras indicadas. A noção de antecipação pedagógica é introduzida. Defende-se o uso da rede social Facebook como mais uma possibilidade de desenvolvimento profissional docente.

Palavras-chave: Facebook, AVA, disciplina, mestrado, antecipação pedagógica.

\section{Abstract}

This article comes from an investigation about social networks as a possibility to the teachers to learn. It shows common points between AVA and particular groups on facebook. The group named social inclusion and technologies was part of one optional subject studied in Master education, made up of ten post graduate students with different abilities. The focus of this 
specific subject was the facebook which each one could explore and think about a common subject together, even though they have different point of views. The pedagogical anticipation notion is introduced. We defend the social networks as another way for teacher professional development.

Key words: Facebook, VEL, subject, master, pedagogical anticipation.

\section{Introdução}

Este artigo é um recorte de uma pesquisa de mestrado (SILVA, 2017) que analisou a experiência de uma disciplina optativa da pós-graduação Stricto Sensu em Educação em um grupo fechado no Facebook. Um dos questionamentos que orientou a investigação foi: que singularidades didático-comunicativas podem ser destacadas entre um grupo fechado no Facebook e um ambiente virtual de aprendizagem? Circunscritos a essa inquietação suscitamos reflexões que podem auxiliar formadores sobre a constituição de cenários formativos online; particularmente, explicitaremos algumas especificidades entre um ambiente virtual de aprendizagem (AVA) convencional (do Moodle, por exemplo) e em um grupo no Facebook.

Assumindo que algumas das singularidades ilustradas podem ser determinantes no êxito ou fracasso na constituição e permanência do grupo, é importante reconhecer e problematizar sobre o uso do Facebook como um espaço contemporâneo de educação institucional e, portanto, que demanda práticas de ensino e de pesquisa que promovam a descoberta e o aprendizado de todos os envolvidos (pesquisadores, professores e alunos).

O artigo traz contribuições sobre a constituição de ambiências de interações com o uso de AVA, que também são de interesse para a docência online em Matemática (BAIRRAL; VIANNA, 2017). A antecipação pedagógica surge como uma decisão política e tecnológica para instigar ou orientar docentes e pesquisadores. Como a pesquisa situa-se no âmbito de processos de ensino e de aprendizagem a distância, cabe inicialmente apresentar subsídios que mostrem a transição da EaD para o que atualmente denomina-se Educação Online (SANTOS; WEBER, 2013).

\section{Da educação a distância (EaD) à educação online}

$\mathrm{O}$ avanço da $\mathrm{EaD}$ tem possibilitado a flexibilização dos espaços e tempos. Não é mais necessário estar presente fisicamente, em determinada hora e dia, para interagir. Além disso, plataformas de cursos de $\mathrm{EaD}$ possibilitam a interação síncrona e assíncrona por diversas mídias (videoconferência, chats, fóruns de discussão etc.). 
A história da EaD pode ser dividida em três gerações (MAIA; MATAR, 2007). Segundo os autores, os primeiros escritos encontrados sobre EaD no Brasil iniciam-se em 1904, com o ensino por correspondência. Os materiais eram impressos e enviados pelos correios. Nesse modelo de $\mathrm{EaD}$, a interação era quase nula, pois o aluno aprendia apenas com o uso do material, geralmente, impresso. Estava no material o potencial formativo.

A segunda geração da $\mathrm{EaD}$ é conhecida como geração analógica, pois envolve o uso das mídias como o rádio, a TV, o telefone e os vídeo-tapes. O ponto em comum entre a primeira e a segunda geração é a inexistência da interação, ou seja, o aluno recebia o material, realizava as atividades, as enviava pelos correios e, ao cumprir todas as etapas, concluía o curso e obtinha a sua certificação. Os modelos formativos dessas duas gerações estavam pautados na transmissão de conhecimento e no distanciamento físico dos sujeitos.

A terceira geração, que começa na década de 1990, traz as novidades dos computadores e da internet. Diferentemente das gerações anteriores, esta fase possibilita interações entre os tutores e alunos de forma síncrona (é realizada simultaneamente entre duas ou mais pessoas, em tempo real, exemplo dos chats); e assíncrona (dispensa a participação simultânea das pessoas, tendo como exemplo o e-mail - correio eletrônico). Existe também a convergência das mídias, pois cada uma tinha sua função e era utilizada em determinado aparelho.

Com o boom tecnológico, essas mídias passaram a ser multimídia, ou seja, todas as mídias em um único aparelho, que a princípio era o computador e, com o avanço das tecnologias de informação e comunicação, essas possibilidades aumentaram o processo de interação. A EaD nessa geração ganhou um novo olhar: o modelo de educação passou a contar com a internet e o computador como ferramenta. Assim, a EaD passou a ser on-line e a educação no atual modelo não é mais transmitida e sim construída na interação entre tutores e alunos e entre os próprios estudantes.

Considerando o uso das tecnologias digitais na educação, a educação online pode ser vista como evolução da EaD. Para Santos e Weber (2013, p. 6),

Muitos autores apresentam a educação online como uma evolução das práticas da educação a distância, sendo comum na literatura sobre educação e tecnologia ela ser tratada como a quarta ou quinta geração de EAD, em virtude, principalmente, do desenvolvimento das tecnologias digitais em rede. Em nossa pesquisa, entendemos que a educação online não é meramente uma evolução da EAD; ela é um fenômeno da cibercultura (SANTOS, 2005), uma vez que podemos atribuir à educação online os mesmos princípios da cibercultura. 
O uso da linguagem multimidiática não está mais restrita ao computador físico, ou seja, ao desktop. Essa linguagem tem sido ampliada para outras mídias digitais, como, por exemplo, tablet, celular, mp4 e smartphones. Santos e Weber (2013, p. 6) complementam dizendo que "a educação online se traduz por toda experiência educacional formal que lança mão do digital em rede, sendo utilizada tanto para experiências presenciais, quanto para semipresenciais ou online, no meio corporativo, acadêmico ou informal". Isso vem ampliando as conexões que vão para além dos espaços físicos e que se desdobram em outros espaços virtuais.

Essa ampliação e convergência de mídias permite ao sujeito criar conteúdos junto aos seus interlocutores (colegas ou professor), algo que não acontecia nas gerações anteriores. Com esse avanço, o aprendiz deixa de ser apenas um consumidor e passa a ser um produtor de conteúdos em temas e formatos variados. Quebra-se, portanto, a hegemonia existente em relação à criação de conteúdos na qual poucos produziam para muitos. Rompe-se também com a lógica unidirecional da comunicação, que passa a ser vista como deslocamento físico ou virtual (LEMOS, 2009).

Vivenciamos em nossa pesquisa o exemplo da educação online, em que lançamos mão do digital, tanto das mídias digitais, quanto das mídias sociais para realizarmos nossa pesquisa. Levantando alguns dados sobre as mídias sociais, podemos descobrir que o Facebook é uma rede social que propicia esse deslocamento comunicacional e essa integração de mídias. $\mathrm{O}$ Brasil, em 2015, segundo o site de ranqueamento alexa.com (2015), era o segundo país do mundo onde mais se acessava o Facebook, responsável por 4,0\% dos acessos mundiais. Com o surgimento do Whatsapp e do Instagram, é possível que as estatísticas tenham mudado, mas o Facebook continua sendo um espaço virtual de uso por brasileiros. Mas, enfim, que ambiente usar: um AVA do Moodle (ou similar) ou formar um grupo no Facebook? Essa inquietação será a que norteará nossa reflexão e contribuição nesse artigo.

\section{No que você está 'pensando' ava ou face?}

Nossa primeira preocupação aconteceu antes de decidir sobre o uso do Facebook para a realização da disciplina. Será que vai dar certo esta dinâmica na rede social? Sinceramente? Não foi fácil! Primeiro por conta da decisão da implementação: será Ambiente Virtual de Aprendizagem (AVA) ou rede social? A decisão de escolher uma rede social como espaço de interação de uma disciplina de mestrado foi uma questão política, a de promover o acesso e de refletir sobre limitações ou formas de aprender nesse espaço. Como tudo nesta vida, para saber se vai dar certo ou não, temos que testar, então neste caso não foi diferente. A princípio, ficamos 
receosos, mas quando falávamos com alguns colegas, uns se surpreenderam e outros acharam interessante e diferente esta prática no Facebook.

\section{Criando um grupo no facebook para interagir com professores-mestrandos}

Por ser o segundo site mais usado no mundo e ter ferramentas que podem ser exploradas para o viés educacional, mesmo que não tenham sido criadas com este intuito, é possível observar que há pessoas que exploram essa rede para o uso educacional. Inclusive, na própria pós-graduação da UFRRJ, o uso dos grupos fechados nas disciplinas obrigatórias e em outras disciplinas optativas também era recorrente. No entanto, o uso era desdobrado em troca de mensagens e local de compartilhar os arquivos que seriam discutidos nas aulas presenciais, ou seja, a rede era apenas um meio que dava continuidade ao que acontecia nos encontros presenciais e não o espaço de interação das aulas.

Dessa forma, resolvemos explorá-la na pós-graduação, dessa vez com o oferecimento de uma disciplina optativa, em que nossas discussões aconteceriam naquele espaço e exploraríamos os recursos disponíveis no grupo. Sendo assim, foi criado um grupo fechado na rede social Facebook, que foi utilizado como espaço primordial para nossas discussões e interações.

Figura 1 - Página inicial do grupo

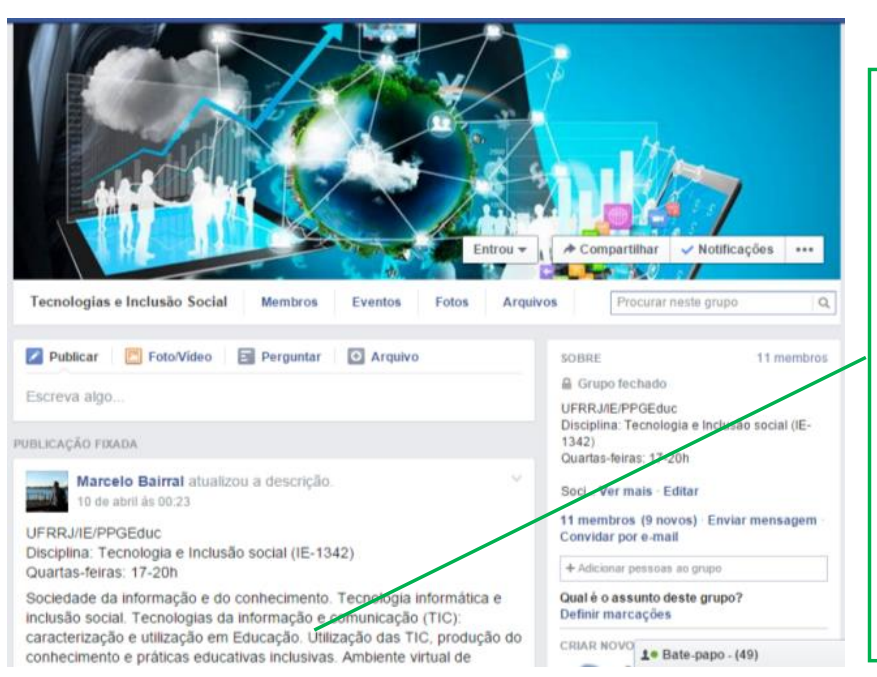

UFRRJ/IE/PPGEduc

Disciplina: Tecnologia e Inclusão social (IE1342)

Quartas-feiras: 17-20h

Sociedade da informação e do conhecimento. Tecnologia informática e inclusão social. Tecnologias da informação e comunicação (TIC): caracterização e utilização em Educação. Utilização das TIC, produção do conhecimento e práticas educativas inclusivas. Ambiente virtual de aprendizagem: conceituação. Discurso, interação, motivação e aprendizagem em ambientes virtuais.

Fonte: Elaboração própria a partir de print de telas

A imagem da Figura 1 ilustra o nosso espaço de aprendizagem no Facebook. Nele nos encontrávamos para debater hipertextualmente (LÉVY, 1993) assuntos voltados para os textos propostos. Para realização da disciplina, o grupo contou com gestão e planejamento semanal, 
que nos orientou durante o período de aulas. Nossas escolhas e interações foram vivenciadas na rede.

O Facebook fornece diversos recursos comunicativos, a facilidade de acesso com a mobilidade e os avanços das redes sem fio. O AVA já possibilita um pouco menos de mobilidade, embora também seja possível acessar do celular. De acordo com Bairral,

A conceituação de ambiente virtual de aprendizagem (AVA) que adoto identifica-o como um complexo sistema interativo onde os seus interlocutores desencadeiam um processo interativo a partir de situações de aprendizagem variadas. Um AVA possui os seguintes componentes: a comunidade constituída e sua intencionalidade, as normas, o propósito educativo, as tarefas de formação, os diferentes espaços comunicativos variados e os artefatos mediadores. Os artefatos podem ser ferramentas físicas ou elementos socioculturais. Sendo um AVA um cenário discursivo particular, ele passa a funcionar em função das demandas sociocomunicativas dos seus participantes. Os participantes não são sujeitos meramente envolvidos no processo. Eles estão imersos no processo, ou melhor, eles pertencem e participam do desenvolvimento sociocomunicativo das interações (2010a, p. 2)

Bairral (2010a), ao conceituar o AVA, descreve alguns componentes que acha necessário e fundamental para a constituição do mesmo. Apesar da disciplina acontecer no grupo do Facebook, as formas de interação (síncrona e assíncrona) são bem parecidas entre a rede social e o AVA. Entretanto, as formas de comunicação no Facebook são bem mais instantâneas do que no AVA. No caso do AVA, o que talvez tenhamos mais delimitados são os espaços comunicativos (chat, e-mail, fórum, mensagens etc.). Para saber o que acontece em um chat ou fórum precisamos logar, entrar no AVA e acessar cada um desses espaços, diferentemente do que acontece no Facebook, que acaba sendo a extensão da vida dos usuários. Por exemplo, ao acordar, a pessoa pega o celular e confere as notificações que receberam durante o período em que esteve dormindo e pode publicar coisas de seu cotidiano. O AVA não tem a mesma característica de ser a extensão da vida dos alunos e sim um espaço onde as pessoas acessam para "estudar", se especializar etc. A dinâmica do Facebook é bem diferente do AVA, pois o Facebook está a todo momento avisando a seus usuários sobre a atualização na rede. No AVA, para saber sobre qualquer coisa que acontece no fórum, o participante ou recebe um e-mail ou tem que acessar o fórum, algo que não acontece no Facebook.

Saímos então dos nossos prédios (que seriam os AVAs), em que nem todos sabem que podem ter acesso, e fomos à periferia da cidade (rede social Facebook) ver como acontece, como é feita a pesquisa em um ambiente onde todos se "sentem em casa" e que se pode ter acesso com mais facilidade. O acesso pelo Facebook facilitou bastante a comunicação, 
possibilitando a mobilidade de estar logado, em nossas contas pelo celular e verificar as notificações avisando quem publicou e quando publicou, diferentemente do que acontece no AVA onde os alunos têm que estar sempre logando para ver se há novas publicações e as entregas de tarefas no AVA, na maioria dos casos, são enviadas em documentos no word, PDF, power point, que sempre exigem maior ligação do usuário ao desktop.

A disciplina ocorreu no primeiro semestre de 2015 e, por acontecer em uma rede social, todos estavam presentes por seus avatares na rede e a relação social acontecia através das interações das postagens dos membros sobre as opiniões que eram demandadas no decorrer da disciplina. Desse modo, os membros tinham acesso às novas publicações, ou seja, eles eram avisados através de uma notificação no globo do Facebook onde poderiam curtir, comentar, concordar, discordar, aumentando desta forma as interações e os hipertextos que apareceram durante a disciplina. Ao contrário, em um AVA, é comum encontrarmos participantes esquecendo senhas, tendo que atualizar seus dados cadastrais de acesso e ficando muitas vezes dependentes do seu e-mail, ferramentas não muito usuais entre jovens e adolescentes.

Outro ponto que foi pensado e repensado durante as discussões do GEPETICEM (Grupo de Estudos e Pesquisas das Tecnologias da Informação e Comunicação em Educação Matemática) foi não trazer a dinâmica da sala de aula presencial para a rede social. Já que a disciplina estava acontecendo em um ambiente diferente do tradicional, teríamos que usar as ferramentas e a linguagem daquele espaço que seria usado como disciplina. Sem quadro, sem giz, sem cadeiras enfileiradas. O curso foi planejado, com ementa, com atividades e datas de entregas, supervisionado e direcionado pelo professor responsável da disciplina. Para Bairral (2007, p. 33),

Quando pensamos em implementar um curso ou qualquer atividade formadora, devemos ter consciência das especificidades do ambiente de aprendizagem a ser implementado. (...) No caso da dinâmica a distância, por envolver espaços físicos e tempos diferentes, o planejamento e a estruturação do cenário são imprescindíveis e exigem um trabalho organizacional prévio significativo. A elaboração e proposição de tarefas constituem um grande desafio.

A programação do curso foi baseada em trabalhar a relação da tecnologia com a inclusão social durante as quinze semanas, explorando as ferramentas e funcionalidades no grupo do Facebook como as que existem no AVA. As pessoas postam seus comentários no fórum de discussão do AVA em determinado horário e os outros participantes interagiam em outros horários. O mesmo aconteceu no Facebook onde os membros publicavam em seus murais e a partir daí os outros alunos respondiam em horários distintos. 
Na comunicação síncrona, ou seja, ao mesmo tempo, de acordo com o cronograma da disciplina teríamos dois chats obrigatórios e aconteceu outro chat opcional, em que todos deveriam estar logados ao mesmo tempo para discutir os conceitos e as dúvidas existentes durante as aulas no Facebook. Embora a disciplina tenha acontecido em um espaço online que estamos acostumados a usar (o Facebook), não foi preciso a ambientação, como acontece no AVA, que geralmente é de uma semana. O fato de todos os participantes já terem suas contas no Facebook e saberem usá-las ajudou bastante nesse processo. No nosso caso, assim que foi solicitada a primeira atividade, a mesma já foi publicada no grupo que gerou comentários e se desdobrou em curtidas e levantamentos de questionamentos.

A relação espaço e tempo tendo como aliada a mobilidade ubíqua, em que não precisávamos estar em um mesmo lugar físico em determinado horário, foi bem explorada pelos membros e possibilitou que os mestrandos e mestrandas participassem de suas casas, trabalhos, da rua, de qualquer lugar que houvesse conexão com a internet. Houve um caso no qual uma aluna precisou se mudar para outro estado, no decorrer do semestre, por questões pessoais, e aproveitando o fato da disciplina optativa ser on-line ela conseguiu concluí-la. Caso a disciplina optativa fosse presencial se tornaria um pouco mais trabalhoso para aluna. Como afirmou Bairral (2007, p. 35),

A formação a distância possibilita uma flexibilidade diferente de um projeto
presencial. Cada conjunto de tarefas é realizado segundo um cronograma pré-
estabelecido e divulgado no início de cada curso. Alguns cursos são
organizados por unidades temáticas, outros por semanas. São propostas
atividades para serem realizadas coletivamente.

Estar online (na rede) e presente nas discussões, mesmo que em outro espaço físico, nos ajudou bastante, pelo fato de cada um ter a flexibilidade de criar seu horário de estudo, de comentar e realizar as atividades no Facebook. A vontade de experimentar outras funcionalidades para o Facebook nos fez buscar trabalhar a disciplina na rede, seguindo a grade de quinze semanas em que foi montado o nosso cronograma de trabalho baseado na ementa a seguir (Quadro 1): 
Quadro 1 - Ementa da Disciplina

\begin{tabular}{|c|c|c|}
\hline Ementa & Organização & Programa Analítico \\
\hline $\begin{array}{l}\text { Sociedade da informação e do } \\
\text { conhecimento. Tecnologia } \\
\text { informática e inclusão social. } \\
\text { Tecnologias da informação e } \\
\text { comunicação (TIC): } \\
\text { caracterização e utilização em } \\
\text { Educação. Utilização das } \\
\text { TIC, produção do } \\
\text { conhecimento e práticas } \\
\text { educativas inclusivas. } \\
\text { Ambiente virtual de } \\
\text { aprendizagem: conceituação. } \\
\text { Discurso, interação, } \\
\text { motivação e aprendizagem } \\
\text { em ambientes virtuais. }\end{array}$ & $\begin{array}{l}\text { * Dinâmica presencial com } \\
\text { atividades e reflexões } \\
\text { paralelas no ambiente suporte } \\
\text { da Disciplina } \\
\text { (www.gepeticem.ufrrj.br) - } \\
\text { participação no Fórum de } \\
\text { discussão } \\
* 2 \text { chats obrigatórios (de } \\
\text { casa): } 15 \text { e } 29 / 05 \text { (13-15h) }\end{array}$ & $\begin{array}{l}\text { Sociedade da Informação e do } \\
\text { Conhecimento: caraterização. } \\
\text { As tecnologias da } \\
\text { inteligência. } \\
\text { Tecnologias e processos de } \\
\text { ensino e aprendizagem. } \\
\text { Produção do conhecimento e } \\
\text { práticas educativas inclusivas } \\
\text { com as TIC. } \\
\text { Discurso, interação e } \\
\text { aprendizagem em ambientes } \\
\text { virtuais. }\end{array}$ \\
\hline
\end{tabular}

Fonte: Elaboração dos autores.

Embora o Quadro 1, na ementa, retrate o AVA, a disciplina ocorreu em uma rede social, diferente do planejado. Na organização, na qual se retrata a dinâmica presencial, esta ocorreu no primeiro e último dia de aula; durante o período da disciplina, as nossas inquietações e participações ocorreram no Facebook. É importante ressaltar que, apesar de ser uma experiência acadêmica na rede, notamos que houve a preocupação em se criar um planejamento, o qual nos foi passado no primeiro encontro presencial, nos deixando cientes de como aconteceria o processo durante o semestre. Ainda na primeira aula, debatemos nossos critérios de avaliação e de participação, pois um dos pré-requisitos para participar da disciplina era ter um perfil no Facebook; caso não tivéssemos, teríamos que criar um. Este não foi um problema encontrado, pelo fato de todos terem seus perfis ativos na rede.

Outro ponto que discutimos previamente foi a possibilidade de o grupo ser desdobrado em uma pesquisa de mestrado, após o término da disciplina. Consideramos que foi a aula do “combinado não sai caro”. Ficou acertado entre o professor e nós, mestrandos, que nossa fonte primordial de comunicação seria a interação no grupo e no chat quando houvesse encontro(s). Cursei a pós-graduação em $\mathrm{EaD}$ na plataforma Moodle que teve apenas dois encontros presenciais, um no primeiro dia do curso e o outro para defender o trabalho de conclusão de curso (TCC). Acessando novamente a plataforma Moodle, na qual cursei a especialização e comparando com a disciplina no Facebook, foi possível notar em alguns momentos diferenças e semelhanças entre as plataformas.

Ao comparar as duas plataformas, temos como dados produzidos a semelhança existente entre o grupo no Face e o AVA no que diz respeito à recuperação de senha. Caso seja necessário 
ou haja a perda ou esquecimento da senha, poderá ser solicitado tanto na plataforma do AVA quanto do Facebook a redefinição da senha. Será enviado por e-mail um link onde o usuário redefina sua senha ou até mesmo a senha descrita.

As diferenças encontradas foram maiores, começando pela forma de acesso e uso. No AVA, as formas de acesso e usos estão direcionadas em grande parte ao desktop; no Facebook, muda um pouco de figura. As formas de uso e acesso se dão em maior número nos dispositivos móveis. A comunicação pelo AVA é restringida pelo acesso ao ambiente, ou seja, há um passoa-passo a ser seguido. No AVA, primeiro se faz o login da conta, depois se acessa a página inicial do Moodle e se busca qual página quer acessar. Ficam disponíveis os módulos que foram concluídos e o discente entra no módulo que está cursando e por último acessa o fórum de discussão. No Facebook, basta ter o aplicativo instalado no aparelho e o mesmo avisa aos membros quando tem mensagem nova.

Para descobrir se realmente o Facebook é mais acessado pelo desktop ou por dispositivos móveis, foi utilizado o recurso do audience insights do business.facebook.com, que nos dá os dados de qual dispositivo o Facebook é mais acessado em todo Brasil. Na primeira imagem temos os dados dos usuários do Facebook que acessam a rede somente pelo desktop.

Figura 2 - Usuários que acessam o Facebook pelo desktop

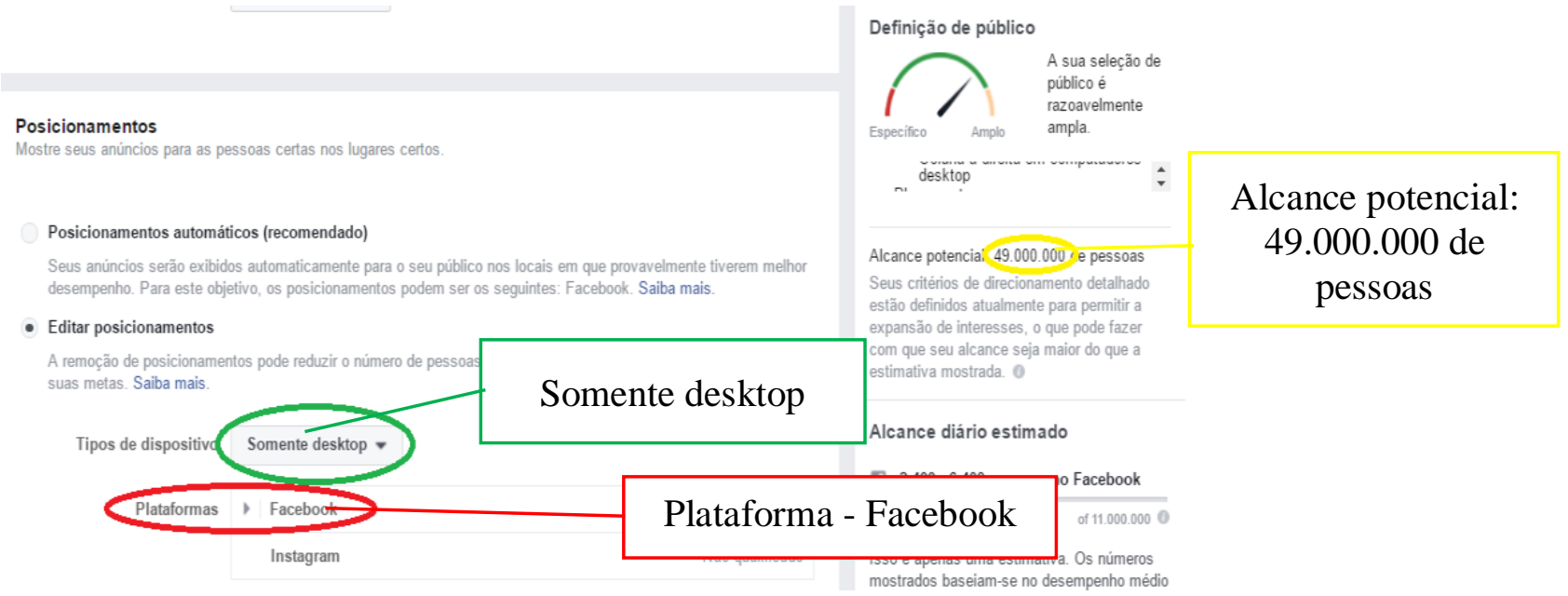

Fonte: Elaboração própria a partir de print de telas

Os dados da imagem acima foram coletados no dia seis de novembro de 2016, e nos fornecem o número de pessoas que acessam somente pelo desktop a plataforma Facebook. Com o alcance potencial, temos o número de 49.000.000 de pessoas. Na próxima imagem, que foi coletada na mesma data, traremos os usuários que acessam somente pelo celular. 
Figura 3 - Usuários que acessam o Facebook pelo celular

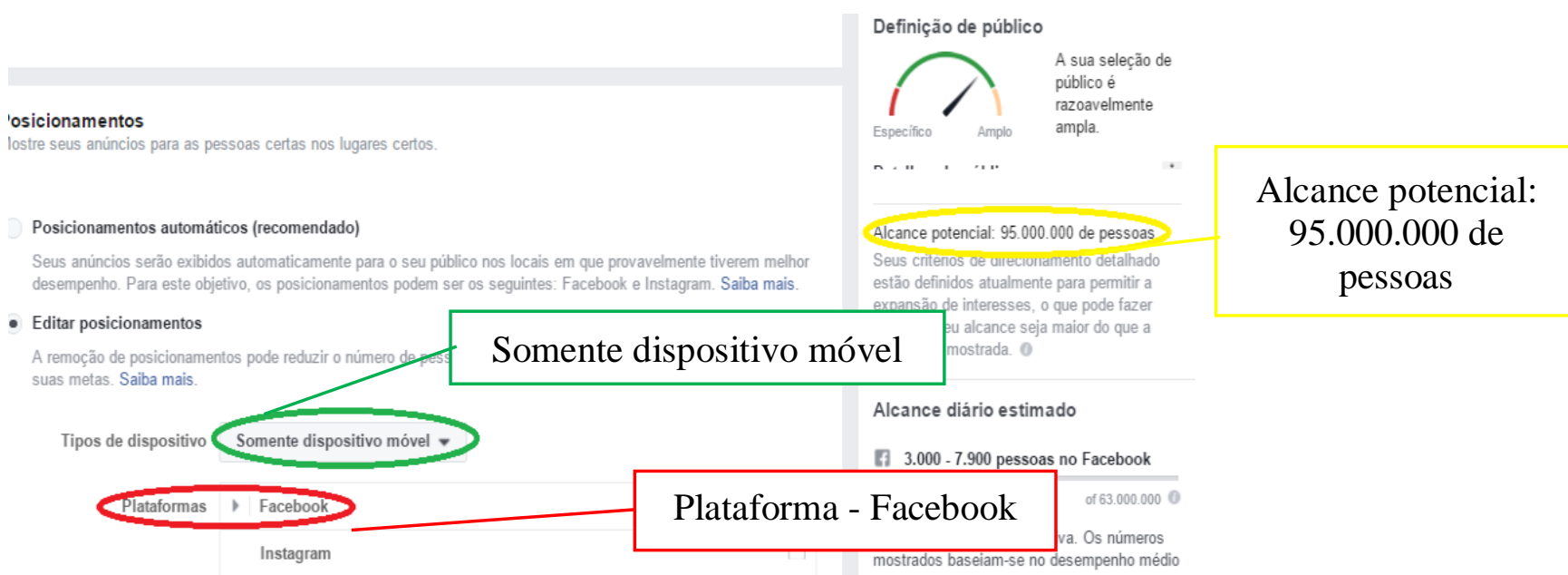

Fonte: Elaboração própria a partir de print de telas

Comparando as duas imagens, temos a noção de que o alcance do uso do dispositivo móvel é quase o dobro referente às pessoas que acessam somente pelo desktop, ou seja, a mobilidade de estar acessando o Facebook pelo celular faz com que as pessoas estejam sempre conectadas, recebendo as notificações, interagindo em suas timelines ou nos grupos dos quais participam.

\section{O grupo e alguns de nossos posts}

Ao entrarmos na página criada para a disciplina optativa, é possível encontrar a descrição e carga horária das nossas atividades (quartas-feiras das 17:00 às 20:00). Apesar dessa organização a disciplina transcorreu a maior parte da sua carga horaria online, conforme acordado com os mestrandos. No grupo eram divulgados os textos, vídeos e imagens e marcados previamente os eventuais encontros presenciais. Além disso, havia cinco abas que poderiam ser exploradas no decorrer da disciplina. Sendo elas: discussão; membros; eventos (onde marcávamos a data de entrega de trabalho e datas dos chats); fotos e arquivos (onde eram adicionados os textos da semana). Para ter mais detalhes sobre como pode ser feita a análise de interações, veja Silva e Bairral (2018).

Para Moreira e Januário (2014, p. 76), “os Grupos que são espaços online criados com um objetivo/interesse particular, e que podem ser úteis para estudantes e professores trabalharem de forma colaborativa".

Na Figura 4 ilustramos um recorte de interações no grupo que foram geradas a partir de uma postagem do professor convidando os membros a contribuírem a partir do texto disponibilizado no grupo. 
Figura 4 - Interações no Facebook

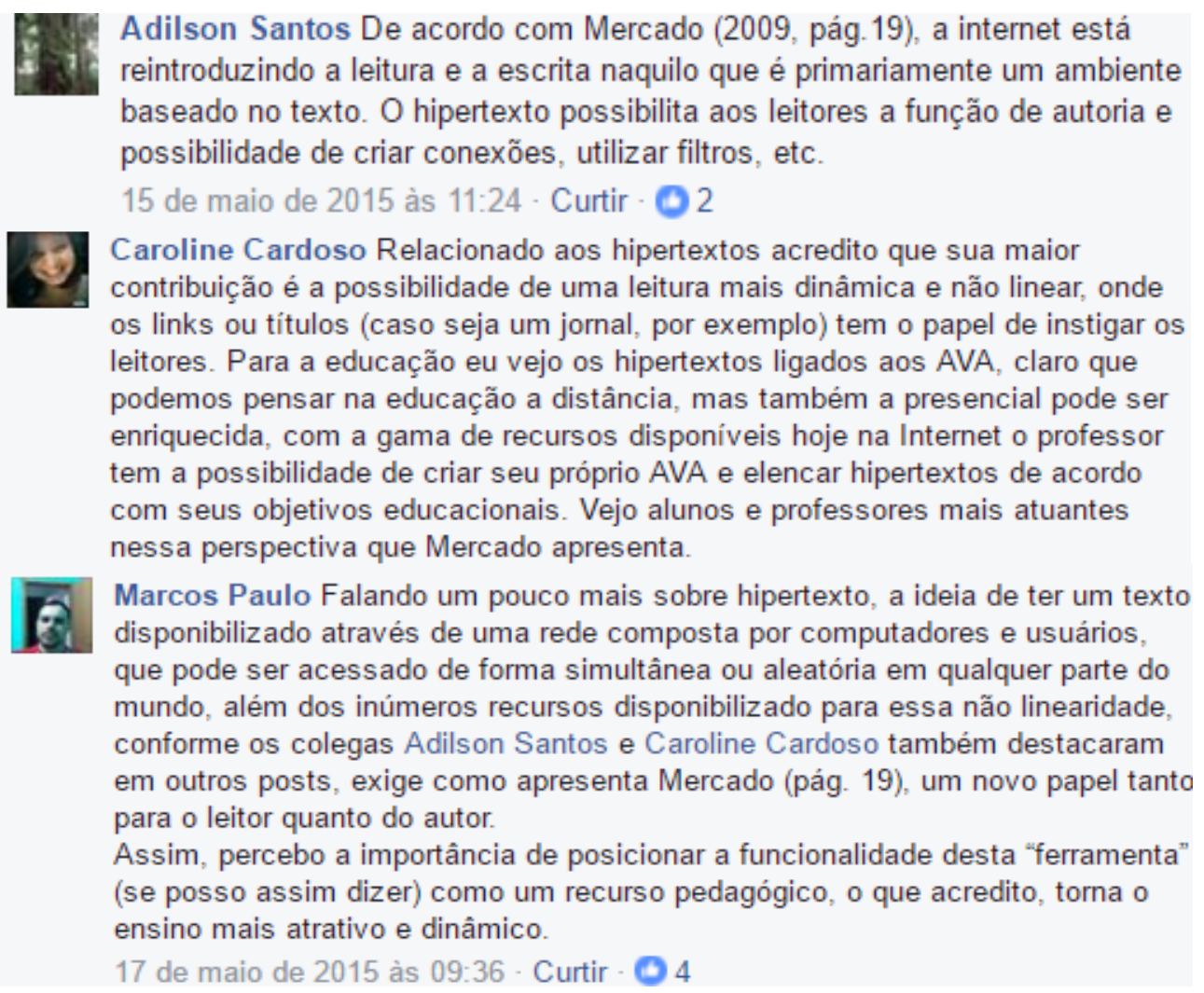

Fonte: Elaboração própria a partir de print de telas

No recorte feito temos exemplos de uma discussão que ocorreu a partir do texto de Mercado (2009), no qual foi explorada a noção de hipertexto (LÉVY, 1993). Dessa forma, temos a postagem onde Adilson e, posteriormente, Caroline fazem uma reflexão e ressaltam a importância da não linearidade do hipertexto e como ele pode servir de material para o professor. Por fim, Marcos expõe seu comentário onde dá continuidade às ideias de Carol e Adilson, fechando com uma síntese, que foi pensada a partir do texto e construída colaborativamente com os colegas citados. Foi o que buscamos desenvolver no curso, um espaço de interesse particular, onde os alunos que estavam inscritos na disciplina pudessem trabalhar de forma colaborativa os conceitos envolvendo tecnologia, inclusão social, interação e hipertexto.

Ao logarmos em nossa conta pessoal, o Facebook nos recebe com a seguinte pergunta: No que você está pensando? Já participando do grupo, a frase é outra. O usuário é recebido com a seguinte chamada para ação: Escreva algo... Dessa forma, os participantes são "estimulados" pelo próprio Facebook a participar/criar (d)as discussões. Além desta diferença, é possível encontrar na caixa de diálogo (conhecido como mural), que fica na página pessoal (perfil do 
usuário) possibilidades de inserir fotos, vídeos, álbuns, fazer check-in, marcar pessoas, dizer o que você está fazendo, além das reações que está sentindo. Falaremos mais à frente sobre as diferenças e semelhanças que existem do mural da página de perfil e da página do grupo.

\section{Publicando...}

Nesse artigo tecemos uma reflexão comparativa (Quadro 2) que pode auxiliar formadores na decisão entre usar um AVA (na plataforma Moodle, por exemplo) ou constituir um grupo fechado no Facebook. Não fossem inquietações e implicações institucionais, nossa decisão pelo uso do Facebook seria tranquila, imediata. Como acreditamos que essa preocupação pode fazer parte do cotidiano de outros profissionais do nosso campo de atuação decidimos socializá-la aqui.

Para responder o questionamento anunciado, no quadro 2 ilustramos semelhanças e diferenças possíveis entre um AVA constituído em uma plataforma e um grupo fechado no Facebook, como foi o nosso caso. Embora um grupo no Facebook possa ser um AVA (BAIRRAL, 2007), as suas particularidades pedagógicas variarão em função da sua natureza, do seu propósito. Ou seja, um grupo constituído de leitores de determinado escritor e um de pesquisadores que estudam a obra desse mesmo escritor terá um desenrolar interativo e formativo diferenciado. De todos os modos, a partir do analisado por Silva (2017), propomos o Quadro 2:

Quadro 2 - Comparação entre AVA e Grupo no Face

(Aqui estamos circunscritos às plataformas Moodle ou Gepeticem)

\begin{tabular}{|c|c|c|}
\hline Elementos & $\overline{\text { AVA }}$ & Grupo no Face \\
\hline Acesso e forma de logar & $\begin{array}{c}\text { Via desktop, na maior parte } \\
\text { das vezes }\end{array}$ & $\begin{array}{l}\text { Desktop e, na parte do tempo, } \\
\text { nos dispositivos móveis }\end{array}$ \\
\hline Ambientação & $\begin{array}{c}\text { É importante o planejamento } \\
\text { contemplar um tempo para } \\
\text { que o sujeito navegue e } \\
\text { conheça seus espaços }\end{array}$ & Desnecessária \\
\hline $\begin{array}{c}\text { Informação sobre } \\
\text { atualização ou produção de } \\
\text { conteúdo } \\
\end{array}$ & $\begin{array}{c}\text { Obtida mediante o acesso ao } \\
\text { ambiente }\end{array}$ & $\begin{array}{l}\text { Alertas e outras formas de } \\
\text { convite enviados } \\
\text { constantemente }\end{array}$ \\
\hline $\begin{array}{c}\text { Recuperação de dados, } \\
\text { senhas }\end{array}$ & Via e-mail & Via e-mail, SMS \\
\hline Formas de uso & No desktop & $\begin{array}{l}\text { No bolso, nas mãos, no celular, } \\
\text { no tablet ... }\end{array}$ \\
\hline $\begin{array}{l}\text { Formas de comunicação e } \\
\text { interação }\end{array}$ & $\begin{array}{c}\text { Necessidade de acesso ao } \\
\text { ambiente }\end{array}$ & $\begin{array}{l}\text { Instantaneamente motivados } \\
\text { pelo aplicativo }\end{array}$ \\
\hline Espaços comunicativos & Maior delimitação & $\begin{array}{l}\text { Menor delimitação e maior } \\
\text { atravessamento entre eles, }\end{array}$ \\
\hline
\end{tabular}




\begin{tabular}{|c|c|c|}
\hline Lógica comunicativa & $\begin{array}{c}\text { Vertical, um para vários, a } \\
\text { partir do proposto pelo } \\
\text { docente e em estratégia } \\
\text { download, ou seja, de } \\
\text { descarregar }\end{array}$ & $\begin{array}{c}\text { muitas vezes com indução da } \\
\text { timeline }\end{array}$ \\
\hline Planejamento & $\begin{array}{c}\text { Horizontal, vários para vários, } \\
\text { baseada no interesse dos } \\
\text { sujes e em estratégias upload, } \\
\text { isto é, de subir, postar }\end{array}$ \\
\hline & $\begin{array}{c}\text { Estruturado em função da } \\
\text { natureza discursiva de cada } \\
\text { espaço comunicativo e das } \\
\text { tarefas, com antecipação } \\
\text { mais detalhada. Mesmo que } \\
\text { exista revisão de tarefa ela } \\
\text { tende a ficar a cargo do } \\
\text { formador }\end{array}$ & $\begin{array}{c}\text { Mais flexível, com antecipação } \\
\text { pedagógica mais negociada e } \\
\text { ajustada coletivamente ao longo } \\
\text { do processo }\end{array}$ \\
\hline Proposição de atividades & $\begin{array}{c}\text { Necessidade de olhar o } \\
\text { planejamento como um todo } \\
\text { de modo a dosar o tempo } \\
\text { individual ou coletivo }\end{array}$ & $\begin{array}{c}\text { Maior flexibilidade em função } \\
\text { do desenrolar interativo e das } \\
\text { demandas de grupos específicos }\end{array}$ \\
\hline \multicolumn{2}{|c|}{} \\
\hline
\end{tabular}

Fonte: Elaboração própria.

É comum vermos o Facebook sendo usando em diferentes iniciativas em nossas Instituições de Ensino, por exemplo, por coordenadores de curso (de graduação ou pósgraduação), na divulgação de projetos de pesquisas ou extensão ou no acompanhamento de egressos. Todavia, ouvir o oferecimento (parcial ou integral) de uma disciplina no Facebook causa certo estranhamento ou, em alguns casos, proibição. Sendo assim, é preciso acabar com essas restrições, preconceitos e desenvolver investigações que mostrem ser possível, com os devidos cuidados políticos, pedagógicos e éticos, constituirmos qualitativamente espaços de aprendizagem para usos na educação científica e tecnológica. Aqui nos referimos aos projetos de formação online que, de fato, visam melhorar e transformar a Educação, não aos modelos mercenários que visam apenas lucro e colocar grande quantitativo de sujeitos realizando individualmente atividades e sem o acompanhamento pedagógico devido.

Como formadores devemos ousar, criar e analisar criticamente nossas ações. Não podemos ser restritivos, mas oportunizadores de novas e desafiantes práticas formativas. Para tal, a partir da reflexão resumida no Quadro 2, ressaltamos a importância tecnopolítica da antecipação pedagógica (AP) na elaboração e constituição de espaços formativos online. Essa antecipação constitui o conjunto amplo de estratégias pensadas, de modo mais estruturado ou não, para garantir o bom desenrolar da dinâmica formativa em um AVA. Ela pode envolver a preocupação com problemas de dubiedade no enunciado de tarefas, nas facilidades de acesso ao material disponível para realizá-las, na dosagem da carga de leituras, na realização individual ou coletiva e na proposição de tarefas obrigatórias ou optativas, na consideração do tempo que 
deve ser dedicado etc. Enfim, a AP constitui uma reflexão pormenorizada do formador de modo a garantir maior êxito possível no processo formativo.

A antecipação pedagógica é uma ação docente que busca evitar muitos atropelos que podem dificultar o aprendizado ou até mesmo causar o abandono do aprendiz. Problemas informáticos, didáticos, linguísticos, motivacionais etc. são sempre objetos de atenção na antecipação pedagógica. Embora a AP não ocorra apenas no design (SANTOS; WEBER, 2013) inicial de um curso é nesse momento que ela deve ter maior centralidade. A partir de Bairral (2010b) é importante ressaltar que a AP não pode apenas ficar circunscrita à prática avaliativa.

Não queremos dizer que o Facebook é melhor que um AVA no Moodle. Em nosso grupo de pesquisa não assumimos essa postura polarizadora e restritiva. É possível que ao ter acesso a este artigo o leitor saiba de outra rede social com maior utilização e ainda mais providencial. Por exemplo, quando estávamos finalizando este artigo o Whatsapp e o Instagram já passavam a ser mais referenciados nas conversas dos coletivos que participávamos.

Ao utilizarmos o Facebook como possibilidade de oferecimento de uma disciplina conhecemos e exploramos diversas estratégias (postagens de formatos variados) e ferramentas comunicativas (planejamento e realização de chats variados no inbox, por exemplo), inclusive, alguns encontros em tempo real aconteceram via chats, que foram marcados previamente. Paralelamente, usamos também outras plataformas de interação síncrona como o Skype e o Virtual Math Team. Com o devido planejamento todas podem ser integradas e usadas na formação online, seja ela total ou parcialmente a distância.

Apesar da volatilidade e plasticidade do Facebook (SILVA, 2017), ele também trouxe possibilidades de registros variados, em formatos de vídeos, imagens, fotos e textos, uma forma dinâmica e hipermidiática de produção e compartilhamento de conteúdo e de interagir. Convidamos você leitor a usar ou integrar uma rede social em seu espaço formativo e a socializar sua experiência, que não pode estar apenas pautada na decisão pela tecnologia mais recente, mas pelo seu potencial realmente transformador na vida e no aprendizado de todos os envolvidos.

\section{Referências}

BAIRRAL, M. A. Discurso, interação e aprendizagem matemática em ambientes virtuais a distância. Seropédica: Edur, 2007.

BAIRRAL, M. A. A educação matemática em ambientes virtuais. In: ENCONTRO NACIONAL DE EDUCAÇÃO MATEMÁTICA - ENEM, 10., 2010, Salvador. Anais... Salvador: Sbem, 2010a. p. 1-9. 
BAIRRAL, M. A.. Estratégias didático-metodológicas na avaliação e formação continuada em ambientes virtuais a distância. In: JAHN, A. P.; ALLEVATO, N. S. G. (Org.).

Tecnologias e Educação Matemática: ensino, aprendizagem e formação de professores. Recife: SBEM-DNE, 2010b, v. 7, p. 85-104.

BAIRRAL, M. A.; VIANNA, M. A. Usando o inbox Facebook como espaço para modelagem de funções matemáticas. In: ASSIS, A.; MARQUES, W. (Org.). Ambientes virtuais e formação de professores: de construções individuais às interações coletivas. Seropédica: Edur UFRRJ, 2017. p. 73-90.

LEMOS, A. Cultura da mobilidade. Famecos, Porto Alegre, v. 1, n. 40, p. 28-35, 2009.

LÉVY, P. As tecnologias da inteligência. O futuro do pensamento na era da informática. Rio de Janeiro: Editora 34, 1993.

MAIA, C.; MATTAR, J. ABC da EaD: a educação a distância hoje. São Paulo: Pearson Prentice Hall, 2007.

MERCADO, L. Integração de mídias nos espaços de aprendizagem. Em Aberto, Brasília, v. 22, n. 79, p. 17-44, 2009.

MOREIRA, J.; JANUÁRIO, S. Redes sociais e educação: reflexões acerca do Facebook enquanto espaço de aprendizagem. In: PORTO C.; SANTOS, E. (Org.). Facebook e Educação: publicar, curtir, compartilhar. Campina Grande: Eduepb, 2014. p. 67-84.

RANQUEAMENTO DE SITES. <www.alexa.com>Acesso em: 11 jul. 2015.

SANTOS, E.; WEBER, A. Educação e cibercultura: aprendizagem ubíqua no currículo da disciplina didática. Diálogo Educacional, Curitiba, v. 13, n. 38, p. 285-303, 2013.

SILVA, B. V. da. A. Curtir, interagir e aprender no Facebook. Seropédica: Edur UFRRJ, 2017.

SILVA, B. V. A. da; BAIRRAL, M. A. Aprender no Facebook: alguns silêncios e ruídos para instigar o ensino e a docência online. Revista Docência e Cibercultura, Rio de Janeiro, v. 2, p. $68-83,2018$. 